\title{
Treatment-resistant depression in adolescents: is the addition of cognitive behavioral therapy of benefit?
}

This article was published in the following Dove Press journal:

Psychology Research and Behavior Management

29 July 2011

Number of times this article has been viewed

\author{
Sarah E Hetrick' \\ Georgina R Cox' \\ Sally N Merry² \\ 'Orygen Youth Health Research \\ Centre, Centre for Youth Mental \\ Health, Melbourne, Parkville, \\ Victoria, Australia; ${ }^{2}$ Werry Centre \\ for Child and Adolescent Mental \\ Health, Department of Psychological \\ Medicine, The University of Auckland, \\ Auckland, New Zealand
}

Background: Many young people with major depression fail first-line treatments. Treatmentresistant depression has various definitions in the literature but typically assumes nonresponse to medication. In young people, cognitive behavioral therapy (CBT) is the recommended firstline intervention, thus the definition of treatment resistance should be expanded. Therefore, our aim was to synthesize the existing evidence of any interventions for treatment-resistant depression, broadly defined, in children and adolescents and to investigate the effectiveness of CBT in this context.

Methods: We used Cochrane Collaboration methodology, with electronic searches of MEDLINE, PsycINFO, Embase, and the Cochrane Depression Anxiety and Neurosis Group trials registers. Only randomized controlled trials were included, and were assessed for risk of bias. Meta-analysis was undertaken where possible and appropriate.

Results: Of 953 articles retrieved, four trials were eligible for inclusion. For one study, only the trial registration document was available, because the study was never completed. All other studies were well conducted with a low risk of bias, although one study had a high dropout rate. Two studies assessed the effect of adding CBT to medication. While an assertive trial of antidepressants does appear to lead to benefit, when compared with placebo, there was no significant advantage, in either study, or in a meta-analysis of data from these trials, that clearly demonstrated an additional benefit of CBT. The third trial showed little advantage of a tricyclic antidepressant over placebo in the context of an inpatient admission.

Conclusion: Few randomized controlled trials have investigated interventions for treatmentresistant depression in young people, and results from these show modest benefit from antidepressants with no additional benefit over medication from CBT. Overall, there is a lack of evidence about effective interventions to treat young people who have failed to respond to evidence-based interventions for depression. Research in this area is urgently required.

Keywords: depressive disorder, treatment-resistant, adolescence, cognitive behavioral therapy, systematic review, meta-analysis

\section{Background}

Depressive disorders in youth are common and debilitating. Point prevalence estimates are $2.8 \%$ in children (aged under 13 years) and 5.7\% adolescents (aged 13-18 years). ${ }^{1}$ By the age of 19 years, between a fifth and a quarter of young people have suffered from a depressive disorder. ${ }^{2,3}$ Those who develop a recurrent or chronic disorder extending into adulthood are likely to suffer considerable disability and impairment. ${ }^{2,4-6}$ The association between depression and completed suicide in young people is of particular concern. ${ }^{7-11}$
Correspondence: Sarah E Hetrick Orygen Youth Health Research Centre, 35 Poplar Rd, Parkville, Victoria 3052, Australia

Tel +613 83872274

Fax +6I3 83872466

Email shetrick@unimelb.edu.au 
Early onset of depressive disorder often indicates a severe illness, with high likelihood of recurrence into adulthood. Approximately $70 \%$ of adolescents with diagnosed depression will relapse within 5 years and are four times more likely to have an adult depressive disorder than adolescents who never experience a depressive episode. ${ }^{12,13}$ The duration of a major depressive episode in young people is in the range of 6-9 months. However, about $50 \%$ of children and adolescents remain clinically depressed at 12 months, and $20 \%-40 \%$ at 24 months. ${ }^{4,14,15}$

Treatment-resistant or treatment-refractory depression is a relatively ill-defined term. Some authors consider depression is refractory to treatment after failure to respond to one adequate antidepressant trial, ${ }^{16}$ and others consider it as failure to respond to two adequate trials of medication. ${ }^{17}$ Most definitions are based on failure to respond to medication rather than to psychotherapy or other interventions. There is an array of systems that categorize different levels of nonresponse to treatment. ${ }^{16}$ From a client's perspective, being relatively free of symptoms is the ultimate goal of treatment, and thus treatment-resistant depression should be defined using Frank et al's ${ }^{18}$ criteria as a failure to achieve remission, which is a period of time during which "the individual is asymptomatic (ie, no longer meets syndromal criteria for the disorder and has no more than minimal symptoms)."

It must be acknowledged that the treatments currently available do not work for all young people. ${ }^{19}$ Failure to respond to first-line treatments with psychotherapy and psychotropic medications is common. ${ }^{20,21}$ In a review of trials of selective serotonin reuptake inhibitors (SSRIs), ${ }^{22}$ the response rates for those treated with fluoxetine ranged from $41 \%$ to $61 \%$, and remission rates were even lower, ranging from $23 \%$ to $41 \%$. This means that a large proportion of young people receiving recommended pharmacotherapy ${ }^{23} \mathrm{do}$ not reach the point of remission, even when taking medication according to guideline recommendations. In a meta-analysis of trials of psychotherapy, $50.4 \%$ of young people had not responded to psychotherapy; in the cognitive behavioral therapy (CBT) subgroup, the number who did not respond was $51.5 \% .^{24}$

Given that depressive disorders are heterogeneous ${ }^{25}$ with complex etiology, including biological, psychological, and social factors, ${ }^{26-29}$ in theory, nonmedication strategies should have a role in their treatment. Indeed, CBT and interpersonal therapy are recommended as first-line interventions for the treatment of adolescent depression in the National Institute for Health and Clinical Excellence guidelines in the United Kingdom and in the practice parameters for the treatment of depression published by the American Academy of Child and Adolescent Psychiatry. ${ }^{23,30,31}$ CBT is the most studied psychotherapy for young people with depression. ${ }^{32,33}$ CBT was developed on the basis of Beck's cognitive model of depression. ${ }^{34}$ In CBT, people learn to monitor and evaluate their thoughts, identify different levels of mood in themselves, recognize thoughts and behaviors that have contributed to this mood and learn how to address these. Several reviews of CBT have been undertaken, one of which showed relatively modest benefits based on continuous outcome measures ${ }^{31}$ and the other showed clear benefit in terms of rates of response to the intervention. ${ }^{24}$ Interpersonal conflict is well known as a risk factor for the development of depressive disorder in young people, ${ }^{4,29,35}$ so some CBT programs for young people include components addressing interpersonal relationships and conflict resolution. A specific therapy to address these issues, ie, interpersonal therapy, has also been shown to be effective with young people who have depression. ${ }^{24}$

Given the treatment recommendations for children and adolescents, it is striking that the definitions of treatmentresistant depression assume that medication will be the first intervention that is trialed, and nonresponse to medication is the criterion used to determine treatment resistance. In the field of treatment-resistant depression in adults, CBT has been investigated as an augmentation strategy. ${ }^{36,37}$ The current definitions of treatment resistance should be broadened to include failure to respond to any treatment. Studies of treatment resistance that include failure to respond to psychotherapy and other interventions are needed to ensure that a young person failing any first-line treatment receives further intervention to prevent the potential longterm negative impacts of persistent depression.

The aim of this review was to synthesize the existing evidence of any interventions for treatment-resistant depression in children and adolescents, including persisting depression after psychotherapy or medication. We have defined treatment resistance broadly, and included any trial that had as one of its aims the treatment of young people with treatment-resistant or persistent depression.

\section{Methods}

\section{Search strategy}

The MEDLINE, PsycINFO, and Embase databases were electronically searched from inception to February 2011. MEDLINE was searched using the following keywords, and where applicable, mapped onto Mesh headings: ("depression" or "depressive disorder" or "depressive disorder, major" or 
"dysthymic disorder" or "mood disorders") (in major Mesh heading field only) AND (resistant or refractory) (in title field only) and (Adolescent or Adult or Infant+ or Child+ or Aged+ or Middle Aged) (in SubMesh heading field only) AND (clinical trial* or AB clinical trial* or $\mathrm{MH}$ clinical trial* or RN clinical trial* random* or AB random* or $\mathrm{MH}$ random* or RN random* placebo* or AB placebo* groups) in title and publication type fields only. PsycINFO and Embase were searched using similar search strings, adapted for each individual database's search engine and Mesh headings (contact authors for full search strategies).

The Cochrane Collaboration Depression Anxiety and Neurosis Group Clinical Trials Registers (CCDANCTR) were searched. CCDANCTR-Studies Register was searched using the following terms: condition $=($ depress $*$ and "treatment resistant") and age group $=\left(\right.$ child* or adolescent $\left.{ }^{*}\right)$.

The CCDANCTR References Register was searched using the following terms:

Title/Abstract/Keywords $=($ depress $*)$ AND $($ adolesc $*$ or preadolesc* or pre-adolesc* or boy* or girl* or child* or infant* or juvenil* or minors or school* or pediatri* or paediatri* or pubescen* or puberty or student* or teen* or young or youth* or school* or high-school or "high school" or college or undergrad $*)$ AND Free-Text $=\left({ }^{*}\right.$ refractory or *resistan*) OR (chronic* or persist*) OR (recurren* or remiss*) OR (nonrespon* or non-respon* or "non respon*") OR (treat* or therap*) and fail*) AND \#2(link to studies) = empty.

We also searched the references of the studies included in the review. The titles and abstracts of all articles retrieved in the search were reviewed and the full text was retrieved for any articles that appeared to meet the study criteria. Any uncertainties over inclusion and exclusion were resolved by a discussion between the authors

\section{Inclusion criteria}

We included studies that met the following criteria: any intervention designed to treat children and/or adolescents with treatment-resistant or persistant depression, as defined by the authors; study participants aged 4-18 years; and a randomized controlled trial design. There were no restrictions on language.

\section{Data extraction}

Two review authors independently extracted information on each study, including characteristics of the design, participants, intervention and comparison groups, information about the conduct of the trial in order to assess the risk of bias, and outcome data. Any discrepancies were discussed. We assessed the risk of bias in included studies using the method followed by the Cochrane Collaboration. ${ }^{38}$ Specifically, assessment was made of the conduct of the trial with regard to random sequence generation, allocation concealment, blinded assessment of efficacy and adverse outcomes, blinding of care providers/participants, whether the number and reasons for dropout were reported, if intent-to-treat analysis was done, and how studies were funded.

\section{Statistical analysis}

The primary outcome from the meta-analysis was a clinically meaningful response to intervention, defined as Clinical Global Impressions (CGI) improvement ${ }^{39}$ score $\leq 2$ (much or very much improved). This is a commonly used definition of response in medication trials of young people with depression. ${ }^{4,21,40}$ Secondary outcomes included reduction in clinician-rated and self-rated depressive symptoms on standardized validated symptom measures. Where meta-analysis was appropriate, pooled effect estimates were obtained using the meta-analytic standard software used by the Cochrane Collaboration, ie, the Review Manager statistical software program. ${ }^{42,43}$

For dichotomous outcomes, including response, the risk ratio and the absolute risk reduction were estimated. For continuous outcomes, such as depression symptoms, where absolute values of post-treatment means and standard deviations were given using the same rating scale across trials, these were used to calculate the mean difference, and where different rating scales were used, the standardized mean difference was used.

For all meta-analyses we used the random-effects model with a 95\% confidence interval (CI). Random-effects models are in general more conservative than fixed-effects models because they take heterogeneity among studies into account. With decreasing heterogeneity, the random-effects approach moves asymptotically towards a fixed-effects model. Where meta-analysis was not appropriate, outcome data are presented in table form and results reported by the investigators are discussed in narrative form.

\section{Results}

\section{Description of studies}

In total, 953 articles were retrieved via the search of electronic databases. Of these, 910 were excluded on the basis of title and abstract. Forty-three full text articles were retrieved for closer examination, of which 27 were excluded. A total of four trials (16 articles) were included, some of which had multiple associated secondary publications 


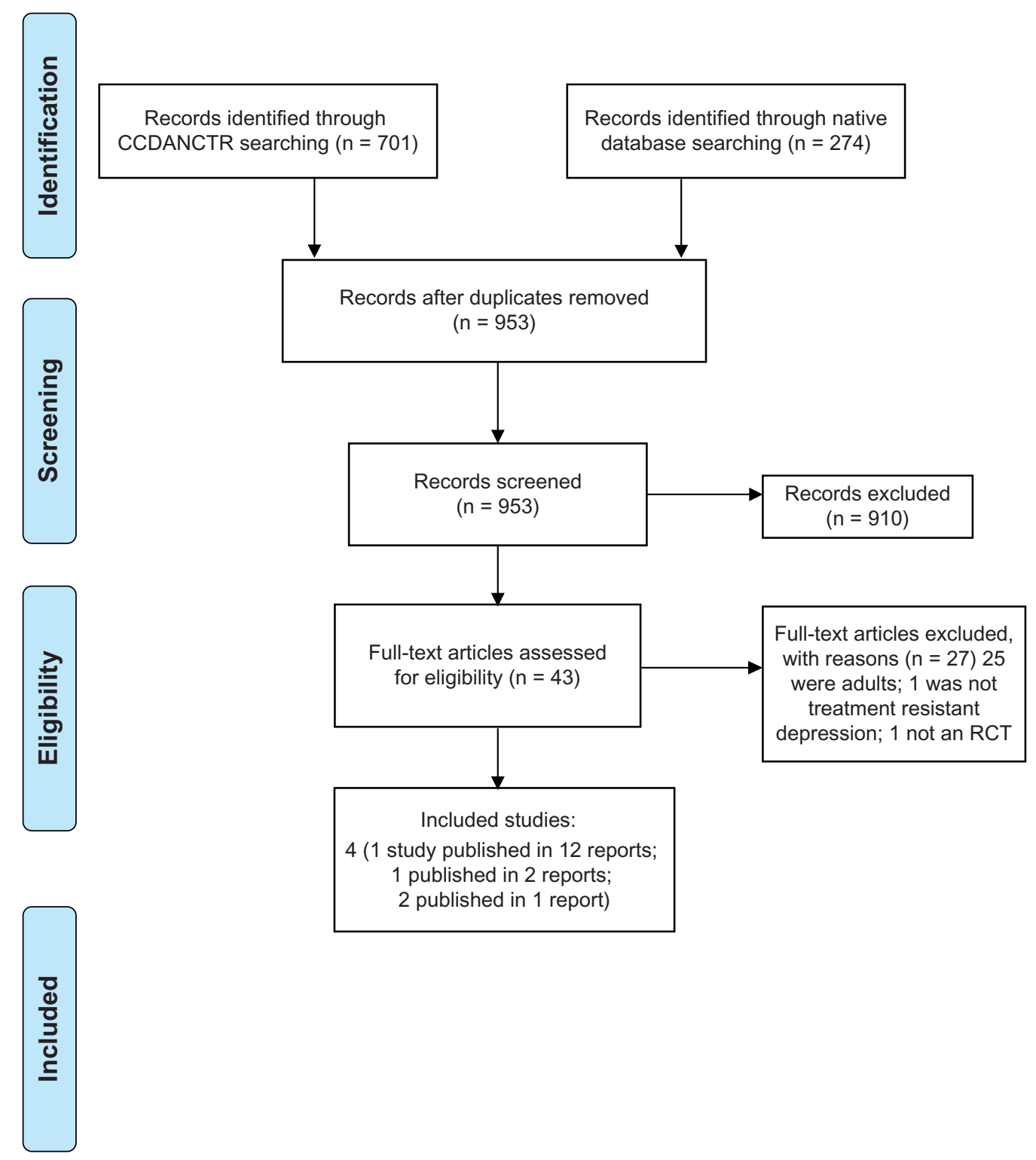

Figure I PRISMA flow diagram of record retrieval and inclusion and exclusion of articles. ${ }^{44}$

Abbreviations: CCDANCTR, Cochrane Collaboration Depression Anxiety and Necrosis Group Clinical Trials Registers; RCT, randomized controlled trials.

(see Figure 1) ${ }^{44}$ For one study ${ }^{45}$ only the trial registration document is available because the study was suspended. There are no reasons for its suspension provided, nor is it clear if recruitment ever started for this trial. The trial was to test the effectiveness of fluoxetine augmented with lamotrigine compared with sertraline in 13-17-year-olds who had not responded to 8 weeks of fluoxetine. This suspended trial will not be discussed further.

Of the remaining three studies, one tested the effectiveness of medication alone; ${ }^{46}$ the Adolescent Depression Antidepressants and Psychotherapy Trial (ADAPT) tested the addition of CBT to routine care plus an SSRI (primarily fluoxetine) compared with routine care plus an SSRI; ${ }^{47}$ and the Treatment of SSRI-Resistant Depression in Adolescents (TORDIA) study included four arms, ie, venlafaxine alone, an SSRI alone, venlafaxine + CBT, and an SSRI + CBT. ${ }^{48}$

The definition of "treatment resistance" varied from study to study. This is likely to have resulted in a difference in the severity of depression in participants in the different trials. In the medication only trial, young people were required to have been referred for a hospital admission due to nonresponse to "several psychosocial (group, individual, and family) and/or pharmacological inpatient interventions." ${ }^{26}$ 
The mean Hamilton Depression Rating Scale (HDRS) score for this group of participants was in the severe range at 22.4, with a mean index episode duration of 61 weeks. Over $40 \%$ were considered suicidal, and at least $25 \%$ of the participants had some comorbid disorder, although this is not well reported.

In the ADAPT trial, an early presentation of the study methodology described its aim as treating "persistent adolescent major depression," 49 with entry criteria being failure to respond, in the initial phase of the trial, to two brief initial sessions of support and educational interventions with a psychiatrist. The sample included 34 adolescents with "proven nonresponse" in that they had failed a trial of psychosocial intervention before being referred into the trial. This was a pragmatic trial conducted in tertiary specialist mental health outpatient clinics and the authors note that "Most participants had already been treated and would have received psychosocial interventions before medication." ${ }^{47}$ The Children's Depression Rating Scale-Revised (CDRS-R) scores were in the moderately severe range, with a median range of index episodes of 40 weeks; $88.5 \%$ had a comorbid disorder, around $40 \%$ in each treatment group experienced suicidal ideation, and $20 \%$ in the fluoxetine group and $12.4 \%$ in the fluoxetine + CBT group reported a previous suicide attempt during their baseline interview.

In the TORDIA study, treatment resistance was defined as a failure to respond to at least 8 weeks of treatment with an SSRI. ${ }^{48}$ Participants in this trial also had moderately severe depression based on CDRS-R scores, and the median duration of the index episode was approximately 68 weeks; $51.5 \%$ had at least one comorbid disorder and $58.5 \%$ had clinically significant suicidal ideation.

Both ADAPT and TORDIA were multisite studies, recruiting 208 and 334 participants, respectively. The ADAPT study recruited via routine outpatient clinical services, while TORDIA recruited via clinical sources and via advertisements. The Birmaher trial ${ }^{46}$ was a single-site study that recruited 27 participants from the inpatient unit in which the interventions were delivered.

The mean age of participants in the trials ranged between 14 years in the ADAPT trial and 16 years in both TORDIA and the trial by Birmaher et al. ${ }^{46}$ In all three trials, the percentage of females was approximately $70 \%$. Only ADAPT and TORDIA had follow-up assessment, lasting 28 and 24 weeks, respectively. Birmaher et al conducted a 10-week acute phase with no follow-up reported. Further details of the included studies are shown in Table 1.

\section{Methodological quality}

\section{Assessment of risk of bias}

A description of the conduct of the included trials and assessment of the risk of bias is presented in Table 2 . All three completed trials gave details of the randomization procedure, which was adequate in all cases, but only one, ie, ADAPT, described adequate allocation concealment. All three studies gave an explicit description of an adequate masking procedure for efficacy outcomes but an adequate masking procedure for adverse outcomes was only undertaken in one study (ADAPT). In trials that included CBT, it was not possible to blind participants and clinicians to the delivery of CBT (ADAPT and TORDIA). In the TORDIA study, after 12 weeks of acute treatment, nonresponders were entered into indicated open-label treatment, which could consist of a higher medication dose, a switch to another medication, augmentation with another medication, CBT, or other psychotherapy. However, the independent evaluator remained blinded.

The attrition rate for the three completed trials varied. It was relatively low in the ADAPT trial $(6 \%$ in the fluoxetine-alone group and $10 \%$ in the fluoxetine + CBT group) compared with the TORDIA study (27\%-29\% in the medication-alone groups and 29\%-30\% in the medication + CBT groups). In the study by Birmaher et al, the attrition rate was $8 \%$ in the medication-only group compared with $36 \%$ in the placebo group. Only one trial (TORDIA) reported on reasons for dropout in sufficient detail to be able to assess whether dropouts were because of side effects of treatment or to worsening depression, and in this trial the reasons were similar across all arms of the trial. In the Birmaher trial, ${ }^{46}$ there were more people withdrawn from the placebo group due to worsening depression than in the medication group. Both TORDIA and the medication-only trial appeared to include all randomized patients in an intention to treat analysis.

The investigators in the TORDIA study reported that their study was underpowered, and while baseline characteristics were mostly similar across all treatment groups, the venlafaxine group had lower Beck Depression Inventory scores and lower rates of post-traumatic stress disorder. There was also a change part way through this study from using paroxetine to citalopram, although this did not affect many participants. It should also be noted that the analysis of outcome data was not on the basis of the way participants were randomized (in a factorial design), but rather according to whether or not they received CBT. 


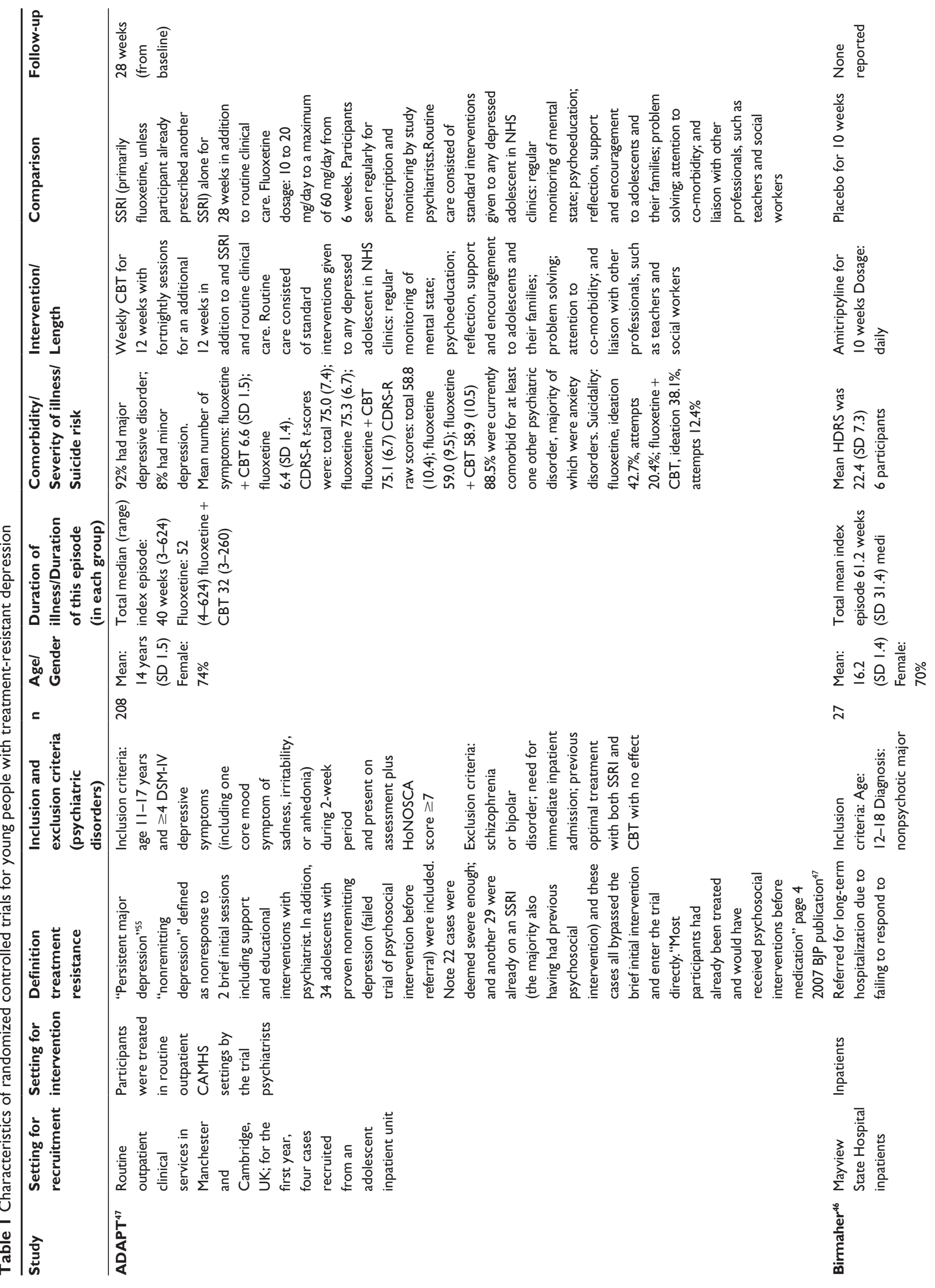




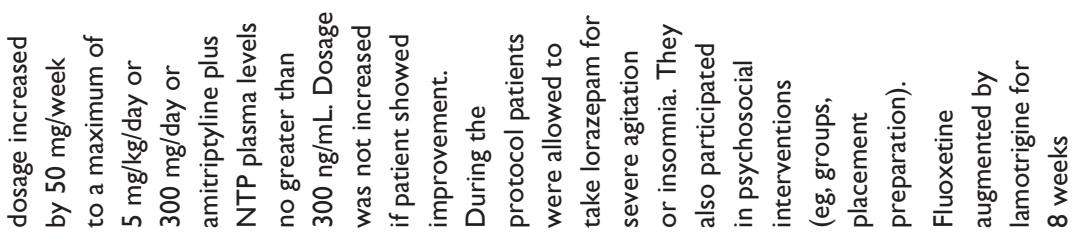
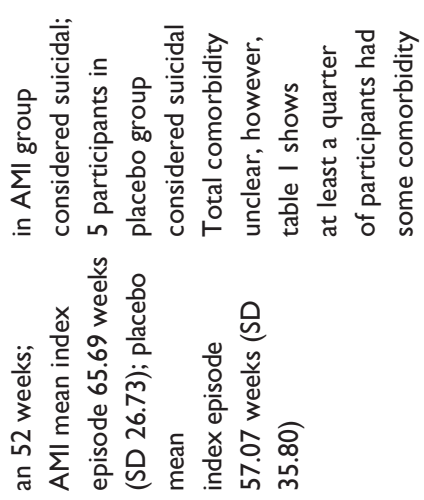

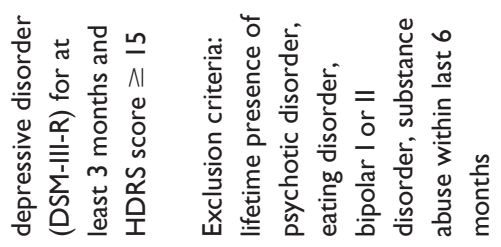

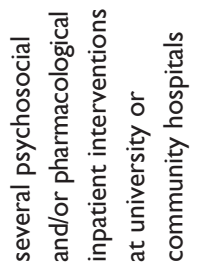

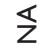

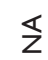

$\stackrel{s}{z}$

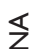

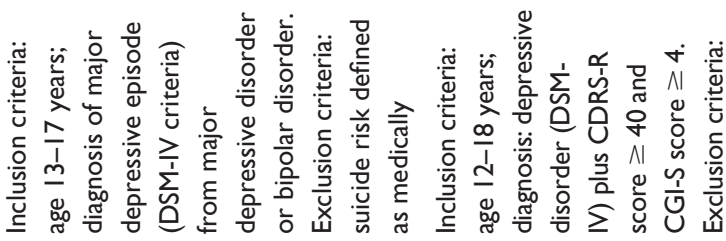

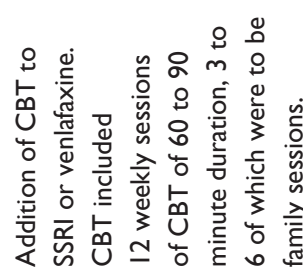

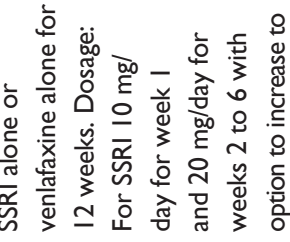

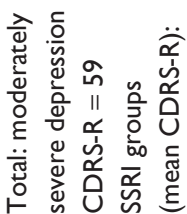

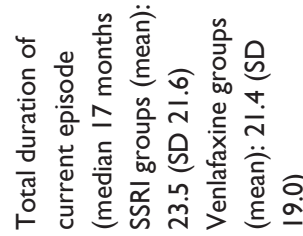

$\underline{\circ}$

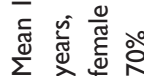

芦 


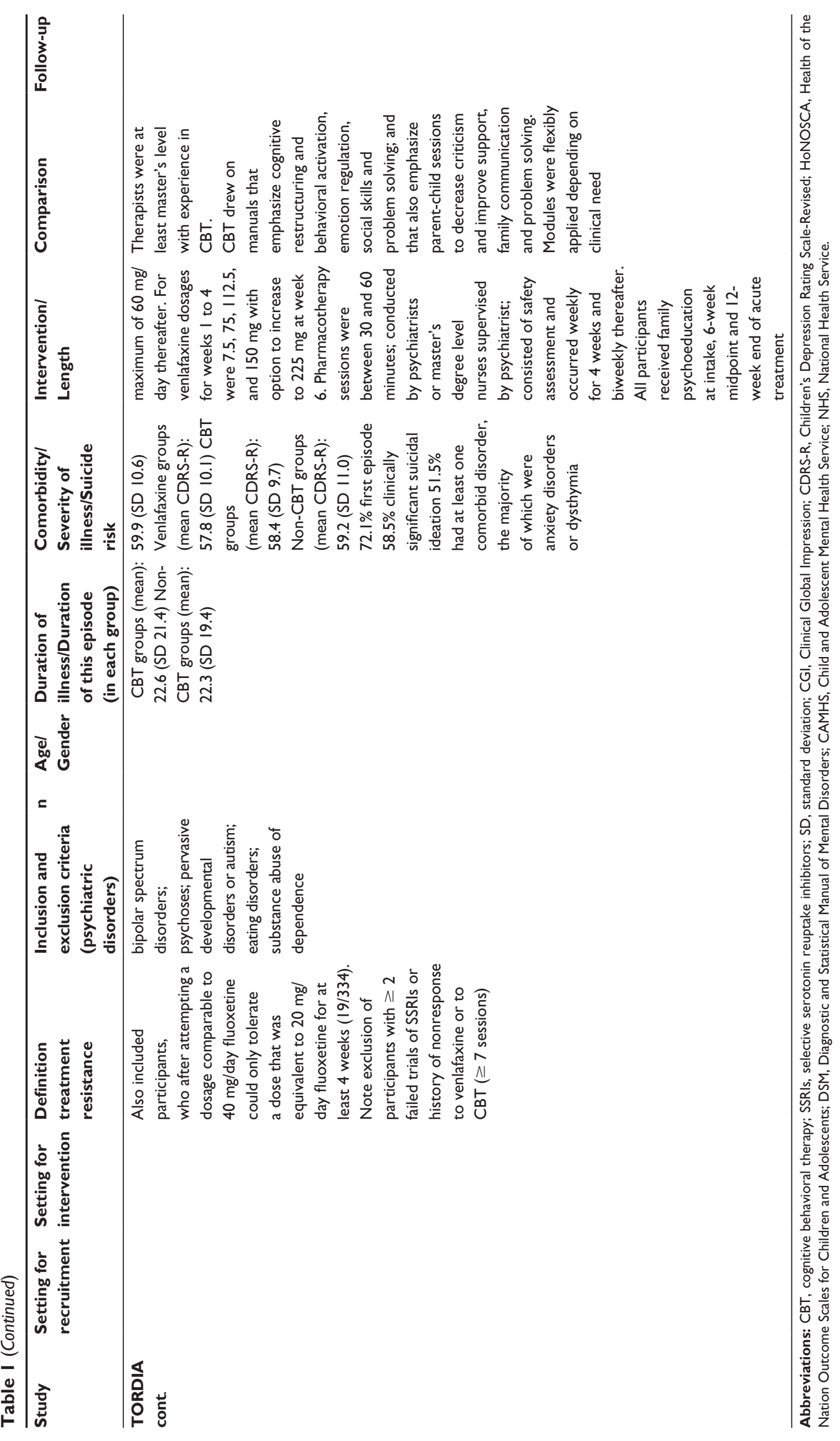


In ADAPT, the study psychiatrists delivered both arms of the intervention, raising the possibility of cross contamination. Routine treatment in both groups included some elements of CBT. There were also additional interventions received as part of routine care, the details of which were not recorded. None of the three completed studies had pharmaceutical funding. Details of the included studies are included in Table 2.

\section{Effects of medical interventions Medication versus placebo}

One trial examined the effects of a medication (amitriptyline, a tricyclic antidepressant) compared with a placebo for participants who had not responded to previous interventions, which included tricyclic antidepressants, sertraline, paroxetine or fluvoxamine, and lithium. Data for this trial are presented in Table 3.

\section{Response}

The trial authors reported that there was no difference between groups in response, with similar numbers no longer fulfilling criteria for major depressive disorder at the end of the study. At the end of the treatment period, $30 \%$ continued to fulfill criteria for major depressive disorder and about $60 \%$ continued to have subsyndromal symptoms. The trial authors report that only an initial self-rated depression score on the Beck Depression Inventory (BDI) predicted response. The investigators also reported that the medication and placebo groups demonstrated similar decreases in the HDRS, and that the two groups had similar decreases in self-rated BDI scores, with no significant difference between the medication and placebo groups.

\section{Addition of CBT}

There were two studies that tested the effectiveness of adding CBT to a medication regimen and some data from these trials could be combined in meta-analysis. It should be noted that the data for the TORDIA study were not presented by the group to which participants were originally assigned, rather results were presented according to whether participants received $\mathrm{CBT}$ or not. In the group receiving medication only, approximately half received an SSRI and half received venlafaxine.

\section{Response}

For response, we used the definition of a CGI score $\leq 2$ (much or very much improved). Based on this definition, the response rates were $43.5 \%$ in the ADAPT study and $47.6 \%$ in the TORDIA study in the groups who received no additional CBT and $42 \%$ in the ADAPT study and 59\% in the TORDIA study in those groups who did receive CBT (see Table 3 ). This equated to a $2 \%$ risk difference between the group who received CBT and the group who did not in the ADAPT study, and an 11\% risk difference between the group who received CBT and the group who did not in the TORDIA study. This difference was not significant when data from both studies were combined (relative risk 0.89, 95\% CI 0.69-1.15, see Figure 2). The ADAPT study included a 28-week follow-up and showed no significant differences between the groups.

Our definition of response was the same as that used in the ADAPT study, and our results are consistent with their reporting. However, the TORDIA study authors defined response as a CGI score $<2$ and $50 \%$ improvement in CDRS-R scores, and found a significantly higher rate of response in the group who received CBT (54.8\%) compared with those who did not (40.5\%). ${ }^{48}$ The authors reported that depression severity at baseline was the strongest predictor of nonresponse. ${ }^{50}$

In the ADAPT study, the primary outcome variable was Health of the Nation Outcome Scales for Children and Adolescents (HoNOSCA). Using this scale, the authors reported nearly identical response rates, with $96 \%$ of young people who received CBT and $98 \%$ of those who did not receive $\mathrm{CBT}$ responding over 12 weeks. In the longer report of the ADAPT study, ${ }^{51}$ the authors defined response as a CGI score $\leq 3$. Based on this definition, they report that $80 \%$ of the participants responded by 28 weeks of follow-up, and estimated that only about $10 \%$ of the trial participants were nonresponders, labeling this group "truly treatmentresistant." They did not report an analysis of predictors of nonresponse. In a meta-analysis of response data using the TORDIA study definition and the ADAPT HoNOSCA definition of response, there was no differences between those who received CBT and those who did not (relative risk 0.86 , 95\% CI 0.39-1.92).

\section{Clinician-rated depression symptoms}

There were no significant differences between groups in clinician-rated depression severity using the CDRS-R (mean difference $0.30,95 \% \mathrm{CI}-3.85$ to 3.26 ) post intervention (see Figure 3). The ADAPT trial reported 28-week follow-up, and there continued to be no significant differences between the groups. The results of the meta-analysis are consistent with the way the results were reported by the individual studies included in the meta-analysis with regard to clinicianreported severity of depression. 
Table 2 Risk of bias

\begin{tabular}{|c|c|c|c|c|c|}
\hline Study & $\begin{array}{l}\text { Randomization } \\
\text { procedure }\end{array}$ & $\begin{array}{l}\text { Allocation } \\
\text { concealment }\end{array}$ & $\begin{array}{l}\text { Blinding of outcome } \\
\text { assessor (efficacy } \\
\text { outcomes) }\end{array}$ & $\begin{array}{l}\text { Blinding of outcome } \\
\text { assessor (adverse } \\
\text { outcomes) }\end{array}$ & $\begin{array}{l}\text { Blinding of } \\
\text { participants/ } \\
\text { care givers }\end{array}$ \\
\hline ADAPT $^{47}$ & $\begin{array}{l}\text { Adequate: } \\
\text { Stochastic } \\
\text { minimization was } \\
\text { used to ensure } \\
\text { balance on } \\
\text { severity, center, } \\
\text { sex, comorbid } \\
\text { behavioral disorder } \\
\text { (probable or definite } \\
\text { oppositional defiant } \\
\text { disorder or conduct } \\
\text { disorder) and } \\
\text { age. Page I5 HTA } \\
\text { report }\end{array}$ & $\begin{array}{l}\text { Adequate: } \\
\text { The study psychiatrist } \\
\text { telephoned an } \\
\text { independent centre, } \\
\text { the Department of } \\
\text { Medical Statistics at } \\
\text { the Christie Hospital } \\
\text { in Manchester, for } \\
\text { randomization. } \\
\text { Page I5 HTA } \\
\text { report }^{51}\end{array}$ & $\begin{array}{l}\text { Adequate: } \\
\text { Outcome assessments were done } \\
\text { by independent evaluators blind } \\
\text { to treatment assignment. Specific } \\
\text { instructions were given to participants, } \\
\text { parents, and treating clinicians not to } \\
\text { disclose treatment assignment to the } \\
\text { blinded evaluator. Page } 15 \text { HTA report }{ }^{51}\end{array}$ & $\begin{array}{l}\text { Adequate: } \\
\text { Adverse events were } \\
\text { recorded at each } \\
\text { assessment interview } \\
\text { (which were conducted } \\
\text { by blind outcome } \\
\text { assessors). Page I0 HTA } \\
\text { report }^{51}\end{array}$ & $\begin{array}{l}\text { Inadequate: } \\
\text { Study compared } \\
\text { CBT with non- } \\
\text { CBT, therefore } \\
\text { participants and } \\
\text { study clinicians could } \\
\text { not be blind to } \\
\text { treatment }\end{array}$ \\
\hline Birmaher ${ }^{46}$ & $\begin{array}{l}\text { Adequate: } \\
\text { "[R]andomly } \\
\text { assigned using a } \\
\text { modification of } \\
\text { Efon's biased coin } \\
\text { toss to match } \\
\text { approximately for } \\
\text { age and gender." } \\
\text { Page } 528\end{array}$ & $\begin{array}{l}\text { Unclear: } \\
\text { No detail }\end{array}$ & $\begin{array}{l}\text { Adequate: } \\
\text { Psychiatric research nurse administered } \\
\text { outcome measurement. "To maintain } \\
\text { blindness of treatment assignment, the } \\
\text { research nurse was unaware of the } \\
\text { results of the side effect evaluations." } \\
\text { Page } 529\end{array}$ & $\begin{array}{l}\text { Inadequate: } \\
\text { The only nonblind } \\
\text { investigator monitored } \\
\text { patients' responses to } \\
\text { treatment, AMI doses, } \\
\text { and presence of side } \\
\text { effects. This investigator } \\
\text { was not involved in any } \\
\text { of the ratings of the } \\
\text { patient." Page } 529\end{array}$ & $\begin{array}{l}\text { Adequate: } \\
\text { "After randomization, } \\
\text { patients received } \\
\text { identical tablets of } \\
\text { placebo or AMI. To } \\
\text { ensure blindness to } \\
\text { treatment allocation, } \\
\text { each patient received } \\
\text { three pills twice a } \\
\text { day." Page } 528\end{array}$ \\
\hline Robins $^{45}$ & $\begin{array}{l}\text { Unclear: } \\
\text { No detail }\end{array}$ & $\begin{array}{l}\text { Unclear: } \\
\text { No detail }\end{array}$ & $\begin{array}{l}\text { Unclear: } \\
\text { States blinding will be maintained by the } \\
\text { comparison group receiving a placebo } \\
\text { augmentation }\end{array}$ & $\begin{array}{l}\text { Unclear: } \\
\text { States blinding will } \\
\text { be maintained by the } \\
\text { comparison group } \\
\text { receiving a placebo } \\
\text { augmentation }\end{array}$ & $\begin{array}{l}\text { Unclear: } \\
\text { States blinding will } \\
\text { be maintained by the } \\
\text { comparison group } \\
\text { receiving a placebo } \\
\text { augmentation }\end{array}$ \\
\hline TORDIA $^{48}$ & $\begin{array}{l}\text { Adequate: } \\
\text { "[U]sing a variation } \\
\text { of Efon's biased coin } \\
\text { toss" page } 904 \\
\text { Note: The study } \\
\text { randomized } \\
\text { participants to an } \\
\text { SSRI depending on } \\
\text { what SSRI they were } \\
\text { already on; ie, it had } \\
\text { to be a switch to } \\
\text { another SSRI }\end{array}$ & $\begin{array}{l}\text { Unclear: } \\
\text { No detail }\end{array}$ & $\begin{array}{l}\text { Adequate: } \\
\text { The intent was for study participants, } \\
\text { clinicians, and independent evaluators } \\
\text { to be blinded to medication treatment } \\
\text { assignment and for independent } \\
\text { evaluators to be blinded to CBT } \\
\text { assignment. Blinding for medication was } \\
\text { maintained by use of } 3 \text { encapsulated } \\
\text { pills daily for all prescriptions, some of } \\
\text { which might be placebo to mask drug } \\
\text { type and dose. The blinding to CBT for } \\
\text { independent evaluators was maintained } \\
\text { by scheduling the independent } \\
\text { evaluator's assessments at a time not } \\
\text { contiguous with CBT sessions and } \\
\text { by asking participants and staff not to } \\
\text { discuss CBT treatment assignment } \\
\text { when the independent evaluator } \\
\text { was present. In } 64 \text { cases, the blinding } \\
\text { of the independent evaluator was } \\
\text { compromised, most commonly because } \\
\text { of participant disclosure of receiving } \\
\text { CBT. Page } 904\end{array}$ & $\begin{array}{l}\text { Inadequate: } \\
\text { Clinicians did the safety } \\
\text { assessments and } \\
\text { "[t]he intent was for } \\
\text { study participants, } \\
\text { clinicians, and } \\
\text { independent evaluators } \\
\text { to be blinded to } \\
\text { medication treatment"; } \\
\text { however they were } \\
\text { not blind to CBT } \\
\text { assignment. Page } 904 \text {. } \\
\text { Many participants were } \\
\text { unblinded during the } \\
\text { continuation phase, } \\
\text { such that the } 24 \text { weeks } \\
\text { outcomes are affected } \\
\text { by lack of blinding }\end{array}$ & $\begin{array}{l}\text { Inadequate: } \\
\text { "The intent was for } \\
\text { study participants, } \\
\text { clinicians, and } \\
\text { independent } \\
\text { evaluators to } \\
\text { be blinded } \\
\text { to medication } \\
\text { treatment"; however } \\
\text { they were not blind } \\
\text { to CBT assignment. } \\
\text { Page } 904\end{array}$ \\
\hline
\end{tabular}




\begin{tabular}{|c|c|c|c|c|}
\hline $\begin{array}{l}\text { Withdrawals } \mathrm{n}(\%) \\
\text { in each group }\end{array}$ & $\begin{array}{l}\text { Withdrawals due to } \\
\text { treatment in each } \\
\text { group }\end{array}$ & Intention to treat analysis & Other & Funding \\
\hline $\begin{array}{l}\text { Adequate: } \\
\text { Fluoxetine alone } \\
\text { Week 12: 6/103 (6\%) } \\
\text { Week 28: I3/103 } \\
\text { (I3\%) } \\
\text { Fluoxetine + CBT } \\
\text { Week I2: II/105 } \\
\text { (10\%) } \\
\text { Week 28: I8/105 } \\
(17 \%)\end{array}$ & $\begin{array}{l}\text { Unclear: } \\
\text { Not enough detail } \\
\text { provided about reasons } \\
\text { for drop out by group }\end{array}$ & $\begin{array}{l}\text { Inadequate: } \\
\text { Included in primary endpoint } \\
\text { analysis: Fluoxetine } 101 / 103 \\
\text { Fluoxetine + CBT 102/105 }\end{array}$ & $\begin{array}{l}\text { Unclear: } \\
\text { I. Study psychiatrists delivered } \\
\text { intervention in both arms so cross } \\
\text { contamination is possible } \\
\text { 2. Routine care stated to include } \\
\text { principles of CBT treatment were } \\
\text { part of routine clinical care; however, } \\
\text { care mainly took the form of advice, } \\
\text { rather than collaborative goal setting, } \\
\text { homework, rewards, and exploration } \\
\text { and challenging of negative cognitions. } \\
\text { Sessions were shorter and fewer } \\
\text { 3. Precise details of any additional } \\
\text { routinely offered CAMHS services } \\
\text { were not systematically assessed }\end{array}$ & $\begin{array}{l}\text { Adequate: } \\
\text { There was no } \\
\text { commercial } \\
\text { sponsorship. } \\
\text { Page 5I HTA } \\
\text { report }\end{array}$ \\
\hline $\begin{array}{l}\text { Adequate: } \\
\text { AMI: I/I3 (8\%) } \\
\text { Placebo: } 5 / 14(36 \%)\end{array}$ & $\begin{array}{l}\text { Inadequate: } \\
\text { Withdrawn from study } \\
\text { due to worsening of } \\
\text { clinical symptoms: AMI: } \\
\text { I Placebo: } 5 \text { Page } 530\end{array}$ & $\begin{array}{l}\text { Adequate: } \\
\text { Stated to be done on page } 529 \\
\text { and table } 2 \text { includes all participants } \\
\text { randomized. Note authors also } \\
\text { undertook completer analysis, } \\
\text { analysis of patients who completed } \\
\text { at least } 4 \text { weeks of treatment, and } \\
\text { stated there was no difference } \\
\text { in outcome. Page } 529\end{array}$ & $\begin{array}{l}\text { Unclear: } \\
\text { I. Small study } \\
\text { 2. Previous treatment ascertained } \\
\text { from medical records, raising the } \\
\text { possibility of incomplete or inaccurate } \\
\text { information, meaning the population } \\
\text { may not truly be treatment resistant }\end{array}$ & $\begin{array}{l}\text { Adequate: } \\
\text { NIMH grant }\end{array}$ \\
\hline NA & NA & $\begin{array}{l}\text { Unclear: } \\
\text { No detail }\end{array}$ & $\begin{array}{l}\text { Inadequate: } \\
\text { Study suspended }\end{array}$ & $\begin{array}{l}\text { Inadequate: } \\
\text { GlaxoSmithKline }\end{array}$ \\
\hline Adequate: & Adequate: & Adequate: & Inadequate: & Adequate: \\
\hline $\begin{array}{l}\text { Venlafaxine alone } \\
22 / 83(27 \%)\end{array}$ & $\begin{array}{l}\text { Venlafaxine alone } \\
\text { Side effect: } 9 \\
\text { Worsening depression: } 3\end{array}$ & $\begin{array}{l}\text { Figure page } 903 \text { and table } 2 \text { page } \\
907 \text { indicate all randomized were } \\
\text { analyzed; with both intent-to-treat } \\
\text { and observed case data presented. }\end{array}$ & $\begin{array}{l}\text { I. There was a change part way } \\
\text { through the study from using to } \\
\text { paroxetine (due to concerns about } \\
\text { efficacy and safety) to citalopram. }\end{array}$ & $\begin{array}{l}\text { National } \\
\text { Institute of } \\
\text { Mental Health }\end{array}$ \\
\hline $\begin{array}{l}\text { Venlafaxine + CBT } \\
30 / 83(36 \%)\end{array}$ & $\begin{array}{l}\text { Venlafaxine }+ \text { CBT } \\
\text { Side effect: } 10 \\
\text { Worsening depression: } 4\end{array}$ & State LOCF data were used & $\begin{array}{l}\text { Of the } 50 \text { randomized to receive } \\
\text { paroxetine only three were in active } \\
\text { treatment at the time of the change } \\
\text { and were removed from the study. }\end{array}$ & \\
\hline $\begin{array}{l}\text { SSRI alone } 25 / 85 \\
(29 \%)\end{array}$ & $\begin{array}{l}\text { SSRI alone } \\
\text { Side effect: } 9 \\
\text { Worsening depression: } 3\end{array}$ & & $\begin{array}{l}\text { 2. Did not meet target recruitment } \\
\text { to satisfy power calculation (required } \\
400 \text { participants). } \\
\text { 3. Baseline characteristics are not }\end{array}$ & \\
\hline $\begin{array}{l}\text { SSRI + CBT } 25 / 83 \\
(30 \%)\end{array}$ & $\begin{array}{l}\text { SSRI + CBT } \\
\text { Side effect: } 13 \\
\text { Worsening depression: } 2\end{array}$ & & $\begin{array}{l}\text { reported by intervention group; } \\
\text { authors report no significant } \\
\text { differences between groups, with the } \\
\text { exception that the venlafaxine group } \\
\text { had lower Beck Depression Inventory } \\
\text { score and lower rates of PTSD }\end{array}$ & \\
\hline
\end{tabular}

Abbreviations: AMI, amitriptyline; CBT, cognitive behavioral therapy; HTA, Health Techology Assessment; LOCF, last observation carried forward; PTSD, posttraumatic stress disorder; SSRI, selective serotonin reuptake inhibitor. 
Table 3 Outcome data

\begin{tabular}{|c|c|c|c|c|}
\hline Study & Response data $(\mathrm{CGI}=2)$ & Response data (trial definition) & $\begin{array}{l}\text { Clinician-rated } \\
\text { depression }\end{array}$ & $\begin{array}{l}\text { Self-rated } \\
\text { depression }\end{array}$ \\
\hline \multirow[t]{6}{*}{ ADAPT $^{47}$} & 12 weeks & 12 week (HoNOSCA - criteria not defined) & 12 weeks CDRS-R & 12 weeks MFQ \\
\hline & CBT 42/I0I (42\%) & CBT 97/IOI (96\%) & CBT 42.5 (16.8) & CBT 22.7 (I5.4) \\
\hline & No CBT 44/I0I (43.5\%) & No CBT 99/I0I (98\%) & No CBT 40.0 (13.9) & No CBT $21.6(14.8)$ \\
\hline & 28 weeks & 28 weeks (HoNOSCA - criteria not defined) & 28 weeks CDRS-R & 28 weeks MFQ \\
\hline & CBT 52/98 (53\%) & CBT 9I/98 (93\%) & CBT $36.4(15.3)$ & CBT $18.9(15.5)$ \\
\hline & NO CBT 57/94 (6I\%) & No CBT $87 / 95$ (92\%) & No CBT 34.6 (13.4) & No CBT I5.5 (I5.0) \\
\hline \multirow[t]{3}{*}{ Birmaher 46} & 10 weeks & 10 weeks ( $\geq 50 \%$ reduction in HDRS) & I0 week HDRS & 10 week BDI \\
\hline & Medication I0/I3 (77\%) & Medication $10 / 13$ (77\%) & Medication 7.7 (8.0) & Medication 10.1 ( 11.8$)$ \\
\hline & Placebo 8/I4 (57\%) & Placebo II/I 4 (79\%) & Placebo 8.6 ( 11.5$)$ & Placebo I0.I (II.I) \\
\hline \multirow[t]{5}{*}{ TORDIA $^{48}$} & 12 weeks & 12 weeks (CGI $\leq 2+\geq 50 \%$ improvement in CDRS-R) & 12 weeks CDRS-R & 12 weeks BDI CBT \\
\hline & CBT 98/I 66 (59.0\%) & CBT $91 / 166$ (54.8\%) & CBT 36.9 (13.9) & II.0 (I I.5) No CBT \\
\hline & No CBT 80/I 68 (47.6\%) & No CBT $68 / 168$ (40.5\%) & No CBT 38.I (12.9) & $10.5(9.8)$ \\
\hline & 24 weeks & 24 weeks & 24 weeks CDRS-R & 24 weeks BDI \\
\hline & Not reported & Not reported & Not reported & Not reported \\
\hline
\end{tabular}

Abbreviations: BDI, Beck Depression Inventory; CBT, cognitive behavioral therapy; CDRS-R, Children's Depression Rating Scale-Revised; HoNOSCA, Health of the Nation Outcome Scales for Children and Adolescents; MFQ, Mood and Feelings Questionnaire.

\section{Self-rated depression symptoms}

There were no significant differences between the groups in self-rated depression severity on the BDI and Mood and Feelings Questionnaire (standardized mean difference -0.06 , 95\% CI -0.23-0.11) post intervention (see Figure 4), or at 28-week follow-up in the one trial (ADAPT) in which this was reported. The results of the meta-analysis are consistent with the way results were reported by the individual studies that were included in the meta-analysis with regard to selfreported depression severity.

\section{Discussion}

\section{Principal findings}

In our systematic review, we identified only three studies investigating the management of broadly defined treatment-resistant depression in young people. Two of these assessed medication and the effect of adding CBT to medication. While an assertive trial of medication showed some benefit, particularly in one study, neither study nor a meta-analysis of data from two trials clearly demonstrated an additional benefit of CBT over and above the medication regimens already in place for any outcome. It should be noted that there was no placebo arm in either of these studies. The third trial showed no advantage of a tricyclic antidepressant over placebo in the context of an inpatient admission. The studies were well conducted with a low risk of bias, although the TORDIA study did have very high dropout rates. ${ }^{48}$ There were no trials of CBT alone or of other psychotherapies, such as interpersonal therapy. Overall, there is currently little evidence upon which to base clinical decisions about interventions for treatmentresistant depression in young people.

\section{Strengths and limitations}

To our knowledge, no other systematic review or metaanalysis of interventional studies for treatment of resistant depression in children and adolescents has been published. We used Cochrane Collaboration methodology, ${ }^{38}$ which ensures clarity and includes an assessment of the possible risk of bias in each study included in the review.

We used a broad definition of treatment resistance to ensure that we included as many clinically meaningful data as possible. However, given the paucity of studies in this area, and the variable definitions of treatment resistance that

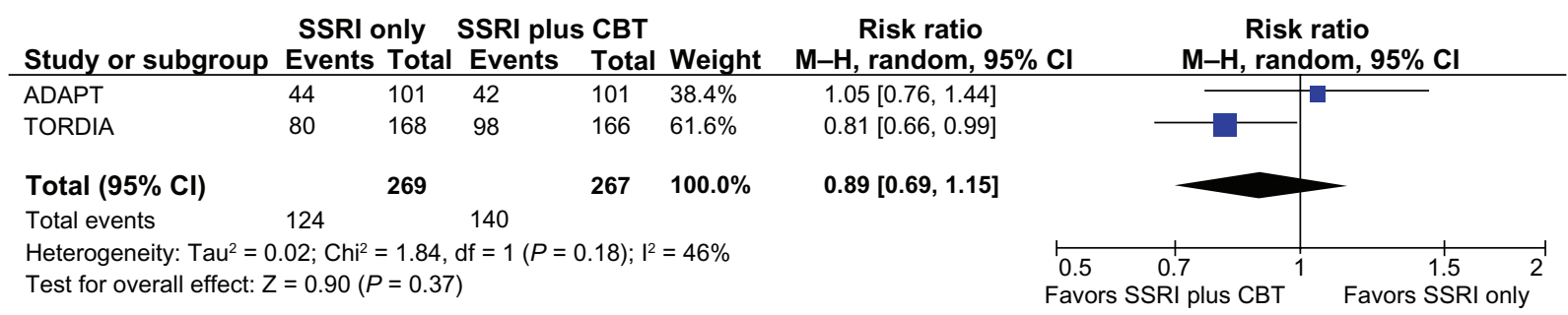

Figure 2 Rates of response $(\mathrm{CGl}$ score $\leq 2)$ in the group who did not receive $C B T$ vs the group who did receive CBT.

Abbreviations: CBT, cognitive behavioral therapy; Cl, confidence interval; CGI, Clinical Global Impressions improvement score; SSRI, selective serotonin reuptake inhibitor. 


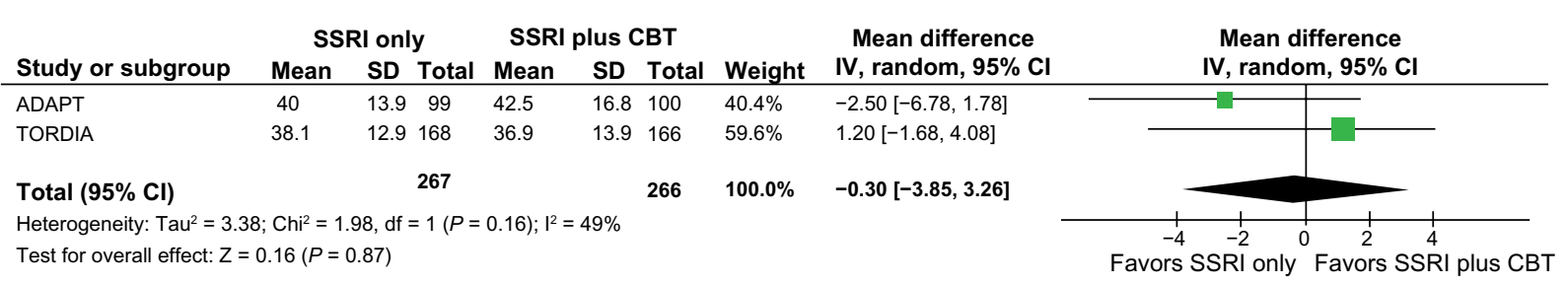

Figure 3 Clinician-rated depression severity scores (Children's Depression Rating Scale-Revised) in the group who did not receive CBT vs the group who did receive $\mathrm{CBT}$.

Abbreviations: $\mathrm{CBT}$, cognitive behavioral therapy; $\mathrm{Cl}$, confidence interval; SD, standard deviation; SSRI, selective serotonin reuptake inhibitor.

were used in each study, we had to be cautious about how we compared the trials in this review.

As is often the case, establishing the most meaningful outcome across diverse studies is a challenge. We used the CGI criteria as our primary outcomes measure. The CGI scale provides a relatively crude estimate of treatment response. We used this measure because data based on this definition were available from both trials, providing some consistency, and because the CGI has been used as a primary outcome variable in a number of studies of treatment of depression in children and adolescents. ${ }^{42,43}$ However, because of the potential limitations of the measure, we also carried out a meta-analysis of response based on the definitions of response in the individual trials (CGI plus CDRS-R for the TORDIA study, and response on HoNOSCA data for the ADAPT study). Although there was a more favorable response rate in those who received additional CBT in the TORDIA study, when findings were aggregated with ADAPT, this finding was not supported.

It is of note that the differences reported in the TORDIA study are relatively small and not maintained at follow-up (according to rates of remission, which were $36.7 \%$ in those who received additional CBT and $41.1 \%$ in those who did not. There were also no significant differences on other outcomes, there were high dropout rates, and the results were not reported according to the groups participants were allocated to, but rather according to whether they received CBT or not. Therefore, post intervention results with regard to response rates should be interpreted cautiously.

Our finding that CBT confers no additional benefit to medication is consistent with findings from two previous studies of young people with depression (although not classed as treatment-resistant). ${ }^{52,53} \mathrm{~A}$ randomized effectiveness trial of adolescents with major depressive disorder of moderate severity, who had recently been prescribed an SSRI, showed only weak effects of additional CBT. ${ }^{52}$ In the Treatment for Adolescents with Depression Study (TADS), while the group on combined medication and CBT improved more than those on either $\mathrm{CBT}$ or fluoxetine alone in the short term, by 36 weeks there was no difference between groups, and a reanalysis of the TADS data showed that combined treatment did not offer any advantage in those participants who were most impaired..$^{53}$

\section{Clinical implications}

Unfortunately many young people do not respond to initial treatment for depression. ${ }^{19}$ The move to an assertive trial of an antidepressant does appear to lead to benefit, especially in the ADAPT trial, although it should be noted that previous treatment in this trial was predominantly psychosocial. In the medication only study, Birmaher et $a{ }^{46}$ hypothesized that young people recovered regardless of the group they were in due to the effect of removing them from their environment into an inpatient setting, potentially decreasing the stress they had been experiencing, stating the entire sample came from "disorganized and conflict-ridden families." The authors of this trial (Birmaher et $\mathrm{al}^{46}$ ) also hypothesized that the improvement in symptoms that participants in this trial experienced might have been due to them receiving positive attention from the research nurse who also motivated the participants to remain in the study. In the TORDIA study, pharmacotherapy sessions were 30-60 minutes in length and

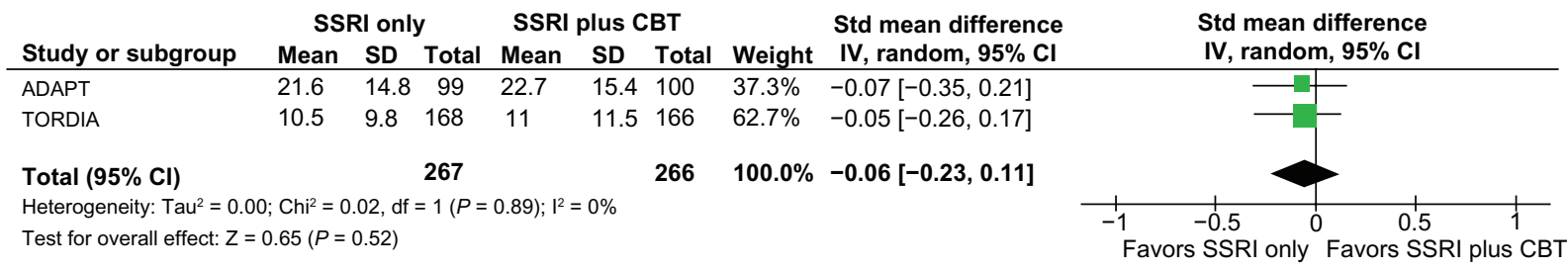

Figure 4 Self-rated depression scores (MFQ and Beck Depression Inventory) in the group who did not receive CBT vs the group who did receive CBT. Abbreviations: CBT, cognitive behavioral therapy; Cl, confidence interval; MFQ, Mood and Feelings Questionnaire; SD, standard deviation; SSRI, selective serotonin reuptake inhibitor. 
consisted mostly of safety assessments, but participants also received family psychoeducation sessions at the beginning, midpoint, and end of the intervention period. In the ADAPT trial, which was a pragmatic trial by design, the participants were all receiving standard care, which included routine monitoring, psychoeducation, support, and encouragement to the young person and their families, problem-solving, attention to comorbidity, and liaison with schools and social workers as required. From these studies, it is impossible to know whether CBT on its own may lead to improvement for treatment-resistant young people, or whether CBT should be started first and medication added if the need arose.

Both the TORDIA study and the study of medication only ${ }^{46}$ showed that nonresponse to the interventions was predicted by more severe symptoms. Therefore, and consistent with guideline recommendations, ${ }^{23}$ CBT may be best reserved for first-line intervention. We propose that treatment resistance should be defined as a failure to respond to an adequate trial of an evidence-based psychological intervention, followed by a failure to respond to the addition of an adequate trial of fluoxetine.

An adequate trial of an intervention such as CBT needs to be more clearly articulated. The lack of effectiveness of additional CBT shown in the studies included in this review may, for example, be due to the "dose" of CBT that was received. Both ADAPT and TORDIA comment on the relatively small number of CBT sessions that young people in the study received, highlighting that in this population CBT was difficult to deliver, and perhaps to receive, in this treatment group. Again, a secondary analysis of the TORDIA dataset showed that those who received fewer than nine sessions of CBT were less likely to respond. It has been argued that there is a "dose X technique" minimum threshold for the core components of CBT. ${ }^{54}$ It may be that, especially for those with more severe depression, an adequate response to medication is required before a young person can properly engage in psychotherapy. ${ }^{52,53}$

\section{Unanswered questions and future research}

A significant proportion of young people in this study did not respond to any treatment. ${ }^{19}$ In the trial by Birmaher et al, ${ }^{46} 30 \%-40 \%$ still had symptoms and functional impairment at the end of the trial. Our study shows nonresponse rates of $40 \%-60 \%$. In the ADAPT study, authors suggest that from the HoNOSCSA scores, nonresponse rates were as low as $10 \%$. However, this percentage does not include a significant proportion of their participants who had only minimal improvement (around $27 \%$ at 12 weeks and $22 \%$ at 28 weeks). It is certainly the case that for a proportion of young people, existing evidence-based treatments are not sufficient and new approaches are required. ${ }^{19}$ There are several avenues that could be pursued further. It is possible that younger populations prefer and respond to interventions that have less emphasis on the cognitive components of CBT. ${ }^{55}$ Analysis of the TADS study suggests that young people respond to more simple models of CBT that focus on one or two core components, such as behavior activation and problem solving. ${ }^{56}$ A meta-analysis of psychotherapy for children and adolescents has shown that "noncognitive" aspects of CBT (such as behavioral activation, problemsolving, group support, and social skills training) were equally effective in treating depression, ${ }^{31}$ so that targeting of specific cognitions may not be necessary. ${ }^{57}$ Indeed, a secondary analysis of data from the TORDIA study showed that CBT participants who received the problem-solving and social skills component of CBT were more likely to respond. ${ }^{58}$ It is a challenge for the field to decipher the treatment mechanism so that the critical aspects of CBT can be delivered. ${ }^{19,54}$ What has not been tested in a pragmatic trial is the effectiveness of adding CBT to standard care for young people similar to those participants in ADAPT who had severe, complex, and persistent depression.

Overall, this review highlights the need for different and more effective therapies for depression in young people. Existing therapies can cure some, and provide some help to many, but a disturbing percentage appear to get little relief from treatment currently available.

\section{Conclusion}

In two well-conducted studies, the addition of CBT to a medication regimen offered no benefit over and above the medication regimen. Overall, there is a lack of evidence about effective interventions to treat young people who have failed to respond to evidence-based interventions for depression. CBT should be reserved for first-line intervention, ensuring an adequate dose delivered over an extended period of time. ${ }^{23}$ In order to avert long-term disability associated with multiple episodes of illness, or persistent depression, research in this area is urgently required. Such studies should be distinct from standard maintenance phases in randomized controlled trials, and involve re-randomization of treatment nonresponders with studies large enough to have power to show differences. The challenges of conducting such studies are considerable. 


\section{Acknowledgment}

We would like to thank the Cochrane Depression, Anxiety, and Neurosis Group for conducting the searches of their trials registers.

\section{Disclosure}

The authors report no conflicts of interest in this work.

\section{References}

1. Costello JE, Erkanli A, Angold A. Is there an epidemic of child or adolescent depression? J Child Psychol Psychiatry. 2006; 47:1263-1271.

2. Lewinsohn PM, Rohde P, Seeley JR. Major depressive disorder in older adolescents: prevalence, risk factors and clinical implications. Clin Psychol Rev. 1998;18:765-794.

3. Lewinsohn PM, Hops H, Roberts RE, Seeley JR, Andrews JA. Adolescent psychopathology: I. Prevalence and incidence of depression and other DSM-III-R disorders in high school students. J Abnorm Psychol. 1993;102:133-144.

4. Birmaher B, Ryan ND, Williamson DE, et al. Childhood and adolescent depression: a review of the past 10 years: Part 1. JAm Acad Child Adoles Psychiatry. 1996;35:1427-1439.

5. Ebmeier KP, Donaghey C, Steele JD. Recent developments and current controversies in depression. Lancet. 2006;367:153-167.

6. Brent DA, Birmaher B. Adolescent depression. NEngl J Med. 2002;347: 667-671.

7. Beautrais A, Joyce PR, Mulder RT, Fergusson DM, Deavoll BJ, Nightingale SK. Prevalence and comorbidity of mental disorders in persons making serious suicide attempts: a case-control study. Am J Psychiatry. 1996;153:1009-1014.

8. Dunn V, Goodyer IM. Longitudinal investigation into childhood- and adolescence-onset depression: psychiatric outcome in early adulthood. Br J Psychiatry. 2006;188:216-222.

9. Fleischmann A, Bertolote JM, Belfer M, Beautrais A. Completed suicide and psychiatric diagnoses in young people: a critical examination of the evidence. Am J Orthopsychiatry. 2005;75:676-683.

10. Nock MK, Borges G, Bromet EJ, Cha CB, Kessler RC, Lee S. Suicide and suicidal behavior. Epidemiol Rev. 2008;30:133-154.

11. Rihmer Z, Akiskal H. Do antidepressants t(h)reat(en) depressives? Toward a clinically judicious formulation of the antidepressant-suicidality FDA advisory in light of declining national suicide statistics from many countries. J Affect Disord. 2006;94:3-13.

12. Richmond TK, Rosen DS. The treatment of adolescent depression in the era of the black box warning. Curr Opin Pediatr. 2005;17:466-472.

13. Weller EB, Weller RA. The serious nature of teenage "blues." J Affect Disord. 2000;61(S1).

14. Kovacs M, Feinberg TL, Crouse-Novak MA, Paulauskas SL, Finkelstein R. Depressive disorders in childhood: I. A longitudinal prospective study of characteristics and recovery. Arch Gen Psychiatry. 1984;41:229-237.

15. Harrington RC. Adolescent depression: same or different. Arch Gen Psychiatry. 2001;58:21-22.

16. Fava M. Diagnosis and definition of treatment-resistant depression. Biol Psychiatry. 2003;53:649-659.

17. Wijeratne C, Sachdev P. Treatment-resistant depression: critique of current approaches. Aust N Z J Psychiatry. 2008;42:751-762.

18. Frank E, Prien RF, Jarrett RB, et al. Conceptualization and rationale for consensus definitions and terms in major depressive disorder. Arch Gen Psychiatry. 1991;48:851-855.

19. Jensen PS. After TADS, can we measure up, catch up, and ante up? $J$ Am Acad Child Adolesc Psychiatry. 2006;45:1456-1460.

20. Brent DA, Holder D, Kolko D, et al. A clinical psychotherapy trial for adolescent depression comparing cognitive, family, and supportive therapy. Arch Gen Psychiatry. 1997;54:877-885.
21. March J, Silva S, Petrycki S, et al. Fluoxetine, cognitive-behavioral therapy, and their combination for adolescents with depression: treatment for Adolescents with Depression Study (TADS) randomized controlled trial. JAMA. 2004;292:807-820.

22. Hetrick SE, Merry S, McKenzie J, Sindahl P, Proctor M. Selective serotonin reuptake inhibitors (SSRIs) for depressive disorders in children and adolescents (Review). Cochrane Database Syst Rev. 2007; 3:CD004851.

23. National Institute for Health and Clinical Excellence. Depression in Children and Young People: Identification and Management in Primary, Community and Secondary Care. Leicester, UK: the British Psychological Society; 2005.

24. Watanabe N, Hunot V, Omori IM, Churchill R, Furukawa TA. Psychotherapy for depression among children and adolescents: a systematic review. Acta Psychiatr Scand. 2007;116:84-95.

25. Slade T, Andrews G. Latent strucure of depression in a community sample: a taxometric analysis. Psychol Med. 2005;35:489-497.

26. Davidson RJ, Lewis DA, Alloy LB, et al. Neural and behavioral substrates of mood and mood regulation. Biol Psychiatry. 2002;52: $478-502$.

27. Goodyer IM, Tamplin A, Herbert J, Altham PME. Recent life events, cortisol, dehydroepiandrosterone and the onset of major depression in high-risk adolescents. Br J Psychiatry. 2000;177:499-504.

28. Cicchetti D, Toth SL. The development of depression in children and adolescents. Am Psychol. 1998;53:221-241.

29. Lewinsohn PM, Roberts RE, Seeley JR, Rohde P, Gotlib IH, Hops H. Adolescent psychopathology: II. Psychosocial risk factors for depression. J Abnorm Psychol. 1994;103:302-315.

30. Birmaher B, Brent D. Practice parameter for the assessment and treatment of children and adolescents with depressive disorders. $J \mathrm{Am}$ Acad Child Adolesc Psychiatry. 2007;46:1503-1526.

31. Weisz JR, McCarty CA, Valeri SM. Effects of psychotherapy for depression in children and adolescents: a meta-analysis. Psychol Bull. 2006;132:132-149.

32. Pers comm; Patrick Callahan, Sarah E Hetrick, Ping Liu, Rosemary Purcell. Fourth Health Research Centre, Melbourne; 2011.

33. Liu V, Callahan P, de Silva S, et al. Evidence mapping in youth mental health. Cochrane Database Syst Rev. 2009;(Suppl 59):1-76.

34. Beck AT. Cognitive Therapy and the Emotional Disorders. New York, NY: International Universities Press; 1976.

35. McCauley E, Pavlidis K, Kendall K. Developmental precursors of depression: the child and the social environment. In: Goodyer IM, editor. The Depressed Child and Adolescent. 2nd ed. Cambridge, UK: Cambridge University Press; 2001.

36. Rush AJ, Kilner J, Fava M, et al. Clinically relevant findings from STAR*D. Psychiatr Ann. 2008;38:188-193.

37. Trivedi RB, Nieuwsma JA, Williams JW. Examination of the utility of psychotherapy for patients with treatment resistant depression: a systematic review. J Gen Intern Med. 2011;26:643-650.

38. Higgins JPT, Green S. Cochrane Handbook for Systematic Reviews of Interventions Version 5.1.0. The Cochrane Collaboration. Available from: http://www.cochrane-handbook.org. Accessed 2011.

39. Guy W. ECDEU Assessment Manual for Psychopharmacology. 2nd ed. Department of Health, Education, and Welfare Publication 76-388. Washington, DC: US Government Printing Office; 1976.

40. Emslie GJ, Rush R, Weinberg WA, et al. A double blind, randomized, placebo-controlled trial of fluoxetine in children and adolescents with depression. Arch Gen Psychiatry. 1997;54:1031-1037.

41. Emslie GJ, Heiligenstein JH, Wagner KD, et al. Fluoxetine for acute treatment of depression in children and adolescents: a placebocontrolled randomized clinical trial. $J$ Am Acad Child Adolesc Psychiatry. 2002;41:1205-1215.

42. The Cochrane Collaboration. Review Manager (RevMan). Version 5.0. Copenhagen, Denmark: The Nordic Cochrane Centre; 2008.

43. DerSimonian R, Laird N. Meta-analysis in clinical trials. Control Clin Trials. 1986;7:177-188. 
44. Moher D, Liberati A, Tetzlaff J, Altman DG; The PRISMA Group. Preferred reporting items for systematic reviews and meta-analyses: the PRISMA statement. PLoS Med. 2009;6:e1000097.

45. Robbins DR, McFarlane W. Lamotrigine in treatment refractory depression in adolescents [clinical trial; webpage on the Internet]. Bethesda, MD: ClinicalTrials.gov: 2006. Available from: http://clinicaltrials.gov/ show/nCT00284791. Accessed July 11, 2011.

46. Birmaher B, Waterman GS, Ryan ND, et al. Randomized, controlled trial of amitriptyline versus placebo for adolescents with "treatment resistant" major depression. JAm Acad Child Adolesc Psychiatry. 1998; 37:527-535

47. Goodyer I, Dubicka B, Wilkinson P, et al. Selective serotonin reuptake inhibitors (SSRIs) and routine specialist care with and without cognitive behaviour therapy in adolescents with major depression: randomised controlled trial. Br J Psychiatry. 2007;335:142.

48. Brent D, Emslie J, Clark G, et al. Switching to another SSRI or to venlafaxine with or without cognitive behavioral therapy for adolescents with SSRI-resistant depression: the TORDIA randomized controlled trial. JAMA. 2008;299:901-913.

49. Harrington R, Dubicka B, Leech A, et al. Randomised controlled trial of fluoxetine and cognitive-behaviour therapy versus fluoxetine alone in adolescents with major depression (ADAPT Trial). Presented at the 30th annual conference of the British Association for Behavioural and Cognitive Psychotherapies, Warwick, UK, July 1-20, 2002.

50. Emslie GJ, Mayes T, Porta G, et al. Treatment of Resistant Depression in Adolescents (TORDIA): week 24 outcomes [NCT00018902]. Am J Psychiatry. 2010;167:782-791.
51. Goodyer IM, Dubicka B, Wilkinson P, et al. A randomised controlled trial of cognitive behaviour therapy in adolescents with major depression treated by selective serotonin reuptake inhibitors. The ADAPT trial. Health Technol Assess. 2008;12(14): iii-iv, ix-60.

52. Clarke G, Debar L, Lynch F, et al. A randomized effectiveness trial of brief cognitive-behavioral therapy for depressed adolescents receiving antidepressant medication. J Am Acad Child Adolesc Psychiatry. 2005;44:888-898.

53. Curry J, Rhode P, Simons A, et al. Predictors and moderators of acute outcome in the Treatment for Adolescents with Depression Study (TADS). J Am Acad Child Adolesc Psychiatry. 2006;45:1427-1439.

54. Weersing VR, Rozenman M, Gonzalez A. Core components of therapy in youth: do we know what to disseminate? Behav Modif. 2009;33:24-47.

55. Asarnow JR, Scott CV, Mintz J. A combined cognitive behavioral family education intervention for depression in children: a treatment development study. Cognit Ther Res. 2002;26:221-229.

56. Brent DA. Glad for what TADS adds, but many TADS grads still sad. J Am Acad Child Adolesc Psychiatry. 2006;45:1461-1464.

57. Brent DA, Maalouf FT. Pediatric depression: is there evidence to improve evidence-based treatments? J Child Psychol Psychiatry. 2009;50:143-152.

58. Kennard BD, Clarke GN, Weersing VR, et al. Effective components of TORDIA Cognitive-Behavioral Therapy for Adolescent Depression: preliminary findings. J Consult Clin Psychol. 2009;77: 1033-1041.
Psychology Research and Behavior Management

\section{Publish your work in this journal}

Psychology Research and Behavior Management is an international, peerreviewed, open access journal focusing on the science of psychology and its application in behavior management to develop improved outcomes in the clinical, educational, sports and business arenas. Specific topics covered include: Neuroscience, memory \& decision making; Behavior

\section{Dovepress}

modification \& management; Clinical applications; Business \& sports performance management; Social and developmental studies; Animal studies. The manuscript management system is completely online and includes a quick and fair peer-review system. Visit http://www.dovepress. com/testimonials.php to read real quotes from published authors. 